\title{
Prediction of Corrosion Rate in RC Structures - A Critical Review
}

\author{
Mike Otieno, Hans Beushausen and Mark Alexander \\ Department of Civil Engineering, University of Cape Town, South Africa
}

\begin{abstract}
Corrosion rate is one of the most important input parameters in corrosion-induced damage prediction models for reinforced concrete (RC) structures. Its accurate assessment and/or prediction is therefore required if the damage prediction models are to be reliably used to predict both the rate and severity of damage and to plan for maintenance of these structures. However, it has not been assigned the level of importance it deserves especially with respect to its prediction. In most cases, instantaneous measurements or constant predicted corrosion rate values are used in damage prediction models hence neglecting its time-variant nature while in some cases, salient factors that affect corrosion rate such as cover cracking and concrete quality and not taken into consideration during the model development. The direct consequence of this may be under- or overestimation of the severity and the time to corrosion-induced damage such as for example cover cracking, and hence service life of the structure. This paper presents a critical review of some of the available corrosion rate prediction models focusing mainly on chloride-induced corrosion. In addition, proposals for the improvement of these models are made.
\end{abstract}

\section{Introduction}

In the light of the paradigm shift to incorporate the corrosion propagation phase $\left(t_{p}\right)$ in the service life of corrosion-affected reinforced concrete (RC) structures [1-3], several models have been developed to predict times to different corrosion-induced damages (limit states) such as cover cracking, loss of steel cross-section area, loss of stiffness, etc [4-7]. Even though these prediction models usually have several input parameters, it is clear that the rate of corrosion governs their outcome either in terms of the time to attainment of a pre-defined limit state or its severity at a given time. A sensitivity analysis by Li et al. [8] showed that corrosion rate $\left(i_{\text {corr }}\right)$ is one of the most important input parameters in the corrosion-induced damage models. 
The success in incorporating $t_{p}$ in the service life of RC structures will therefore depend on how accurately and realistically the $i_{\text {corr }}$ can be predicted. As discussed in later sections, its treatment with respect to prediction does not match the level of importance it deserves. Instead, more focus has been placed on the prediction of corrosion-induced damages, with little attention to the assessment and prediction of $i_{\text {corr }}$. The result of this has been the development of several corrosion-induced damage prediction models for each limit state (e.g. time to corrosion-induced cover cracking). This makes the task of selecting appropriate models difficult for the practicing engineer.

In contrast, the number of available/published $i_{\text {corr }}$ prediction models is relatively small compared to that of the damage prediction models; this shows where the focus has been placed, as mentioned above. This paper presents a review of the available/published $i_{\text {corr }}$ prediction models. It is divided into two main parts: the first part presents a review of individual models while the second part contains a summary of some of the salient aspects that should be incorporated in the models and a brief discussion of an ongoing study on the prediction of $i_{\text {corr }}$.

Before proceeding, it is important to note the following:

(i) $i_{\text {corr }}$ is affected by many factors and can be expressed (using a factorial approach [9]) as follows:

$$
i_{\text {corr }}=f\left(k_{1}, k_{2}, \ldots \ldots, k_{n}\right)
$$

where $k_{1}, k_{2}, \ldots \ldots, k_{n}$ represent the factors affecting corrosion propagation e.g. supplementary cementitious materials, moisture content, cyclic wetting and drying, sustained loading, loading history, concrete resistivity, concrete quality, cover depth, temperature, cracking, dissolved oxygen concentration and exposure conditions [10]. However, it is important to note that it may be impractical to explicitly incorporate each of these factors in a model. Some of these factors can be indirectly incorporated in a predection model e.g. concrete resistivity can be indirectly used to account for temperature, concrete quality and moisture content of the concrete.

(ii) $i_{\text {corr }}$ prediction models can be developed based on one or a combination of the following approaches:

- Electrochemical principles of corrosion of steel in concrete [e.g. 11],

- Statistical analysis of experimental the test results [e.g. 12],

- Electrochemical principles of corrosion and experimental testing [e.g. 13].

(iii) The following factors should be considered in the development of $i_{\text {corr }}$ prediction models:

- The model should be (as far as possible) representative of the actual $i_{c o r r}$ characteristics in the RC structure in its service environment. 
- It should account for variability in both $i_{c o r r}$ and the model input parameters such as cover depth and concrete quality. Furthermore, this variability should be taken into account using adequate and representative data.

- If developed based solely on either electrochemical principles of corrosion or accelerated corrosion test results, its validation using natural corrosion data is important.

- The model should be capable of being adjusted to suit the prevailing concrete and exposure conditions of the RC structure.

With these in mind, the next sections will present a review of the available $i_{c o r r}$ prediction models.

\section{Existing Corrosion Rate Prediction Models}

\section{Alonso et al.'s model (1988)}

The prediction model by Alonso et al. [14] is based on a statistical analysis of resistivity and accelerated carbonation-induced $i_{c o r r}$ results. The experiments were carried out using $20 \times 55 \times 80 \mathrm{~mm}$ mortar specimens made with various binders (Portland cement (PC), Sulphate resistant PC, slag cement, Pozzolanic cement, fly ash (FA) cement and 70/30 PC/FA) with a w/b ratio of 0.50 . Accelerated carbonation was achieved by exposing the specimens to $\mathrm{CO}_{2}$ (in a $\mathrm{CO}_{2}$-filled chamber (concentration not reported) assumed to be $100 \% \mathrm{CO}_{2}$ ) at $50-70 \%$ relative humidity (RH). $i_{\text {corr }}$ was assessed by linear polarisation resistance (LPR) technique and later ascertained using the gravimetric method. The experimental results are presented in Figure 1.

The mathematical expression for the trend-line in Figure 1 was adopted as the prediction model, with concrete resistivity as the main input parameter, Eqn. (2):

$$
i_{\text {corr }}=\frac{k_{c o r r}}{\rho_{e f}}
$$

where $k_{\text {corr }}$ is a constant with a value of $3 \times 10^{4} \mu \mathrm{A} / \mathrm{cm}^{2} . \mathrm{k} \Omega-\mathrm{cm}$ (slope of graph in Figure 1) and $\rho_{e f}$ is the resistivity of the concrete at its actual degree of saturation. Alonso et al.'s [14] experimental results show a clear relationship between $i_{c o r r}$ and concrete resistivity. The following can be noted with respect to this model:

- Accelerated tests were used without validation using natural corrosion test results. The use of small (mortar) specimens $(20 \times 55 \times 80 \mathrm{~mm})$ may have a size effect on the experimental results [15].

- In addition to concrete resistivity, $i_{c o r r}$ in concrete can be affected by other factors such as presence of cracks, concrete cover depth, among others [10]. 
- Variability of $i_{c o r r}$-influencing parameters such as cover depth is not taken into accounted.

- It is not clear whether the $i_{\text {corr }}$ predicted by the model is a constant $i_{\text {corr }}$ or not.

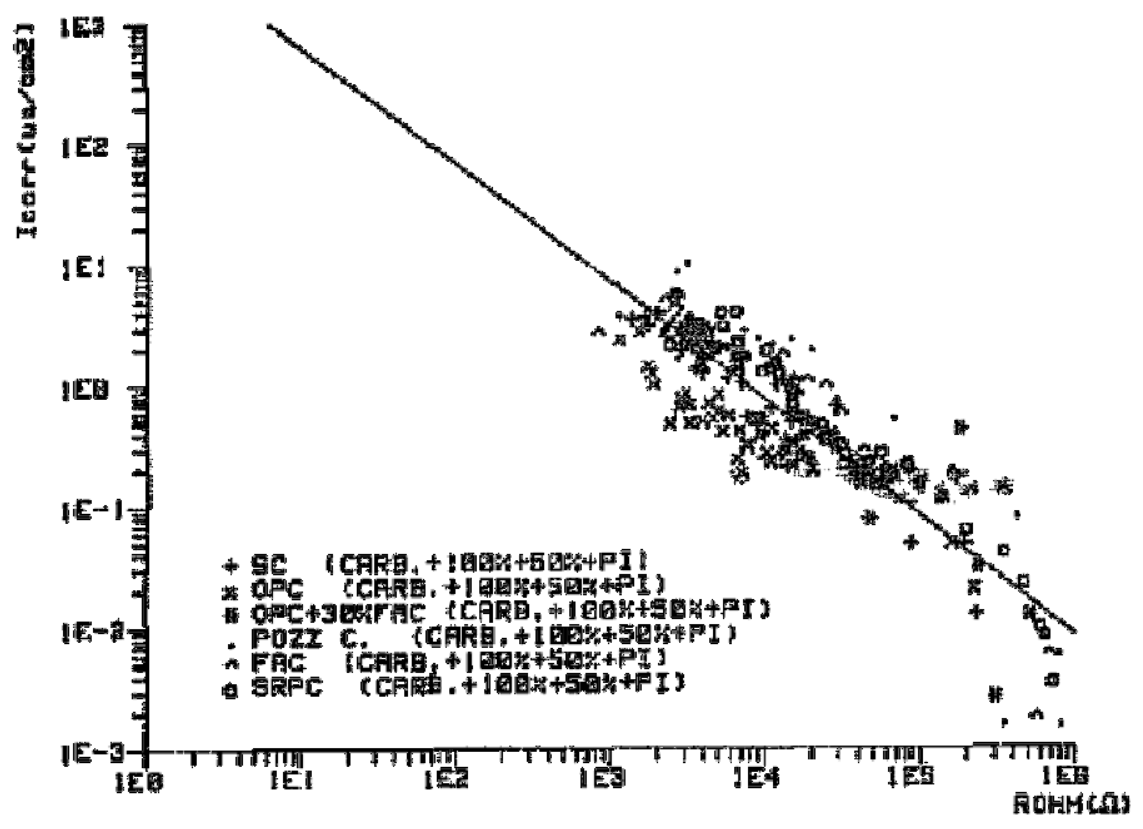

Figure 1: Corrosion rate vs. resistivity (for steel in carbonated mortars) [14]

However, even though shortcomings can be cited with respect to this model, it provides a clear indication of the possibility of using concrete resistivity as a potential durability indicator. The electrical resistivity of concrete provides indications on the pore connectivity and therefore, on the concrete resistance to penetration of liquid or gaseous substances; it can therefore be related to reinforcement durability [16]. The relationship between concrete resistivity and $i_{\text {corr }}$ will be revisited later in this paper.

\section{Yalcyn and Ergun's model (1996)}

The model by Yalcyn and Ergun [17] was developed by studying the effect of chloride and acetate ions on $i_{\text {corr }}$. Corrosion was evaluated by measuring half cell potentials (HCP) and LPR. The model was developed based on results obtained from accelerated corrosion testing (admixed chlorides); with $i_{\text {corr }}$ measurements taken up to a period of 90 days i.e. at 1, 7, 28, 60 and 90 days on cylindrical specimens of $150 \mathrm{~mm}$ diameter x $150 \mathrm{~mm}$ height. Only 90/10 PC/Pozzolanic cement was used. The model is presented as shown in Eqn. (3): 


$$
i_{\text {corr }}=i_{o} e^{-C t}
$$

where $i_{\text {corr }}$ is the corrosion rate at time $t, i_{o}$ is the initial corrosion rate and $C$ is a corrosion constant that depends on the degree of concrete pore saturation, $\mathrm{pH}$, permeability and the cover thickness; Yalcyn and Ergun proposed a value of $C$ (evaluated from $i_{\text {corr }}$ vs. time curves) as $1.1 \times 10^{-3}$ day $^{-1}$ for the different concrete samples they considered. Important notes about the model are as follows:

- The model predicts $i_{\text {corr }}$ in uncracked concrete and may therefore not be applicable to cracked concrete; where both corrosion initiation and propagation may be affected (shortened or eliminated) [18].

- Factors which affect $i_{\text {corr }}$ such as cover depth, temperature, concrete resistivity and cracking, among others [10], are not incorporated in the model.

- It is not clear whether the $i_{\text {corr }}$ predicted by the model is a constant $i_{\text {corr }}$ or not.

- The model as presented in Eqn. (3) assumes that the concrete and environmental conditions remain constant and that future $i_{\text {corr }}$ is only dependent on time. However, these factors may vary from time to time and consequently affect $i_{\text {corr }}$.

- Taking into account that the model was developed using accelerated corrosion results, validation of the model should be carried out using data from natural corrosion tests.

\section{Katwan et al.'s model (1996)}

Katwan et al. [19] proposed an empirical model, based on the electrochemical noise $(\mathrm{ECN})$ technique for the determination of $i_{\text {corr }}$. The measurements were made on full-scale RC beams $(150 \times 250 \times 3000 \mathrm{~mm})$ under dynamic $(0.17 \mathrm{~Hz})$ and static loading, and exposed to a corrosive environment $(3.5 \% \mathrm{NaCl}$ solution). Results from short and long-term tests suggested that for a given test condition, the $i_{\text {corr }}$ can be predicted from the standard deviation (SD) of the HCP readings obtained using the ECN method.

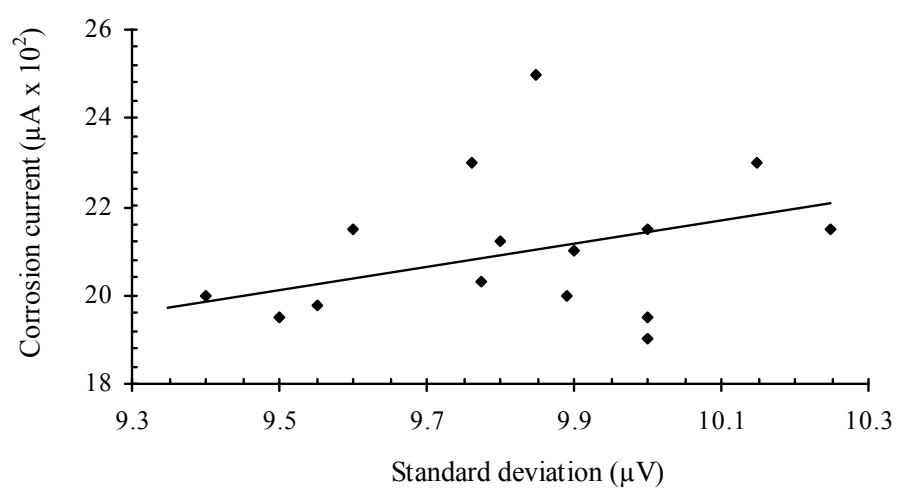

Figure 2: Corrosion current $(\mu \mathrm{A})$ vs. standard deviation of $\mathrm{HCP}(\mu \mathrm{V})[19]$ 
Although Katwan et al. [19] did not provide a mathematical expression for the relationship between corrosion current $(I, \mu \mathrm{A})$ and SD of the HCP from the ECN technique, it is similar to that obtained by Page and Lambert [20] as shown in Eqn. (4):

$$
\log I=0.171+0.823 \log S D
$$

The following can be noted with respect to this model:

- The use of HCP to assess corrosion has been criticised in the past for its instability depending on the prevailing measurement conditions; there is no general correlation between $i_{\text {corr }}$ and HCP [21]. In most cases, for practical applications, HCP measurements need to be complemented with other corrosion assessment techniques e.g. LPR. Consequently, this limits the application of Katwan et al.'s model [19].

- The use of ECN technique in field of RC is not common (or well established) and therefore limits its practical applicability.

- In their paper [19], Katwan et al. reported that the SD was sensitive to change in the rate of sampling by the ECN technique but no recommendation was provided to account for this.

- It is not clear whether the $i_{\text {corr }}$ predicted by the model is a constant $i_{\text {corr }}$ or not.

\section{Liu and Weyers' model (1998)}

Liu and Weyers [12] developed an empirical model based on statistical analyses of experimental results obtained from a 5 year accelerated corrosion testing programme on 44 uncracked bridge deck slabs $(1180 \times 1180 \times 216 \mathrm{~mm})$ with covers of 25,51 and $76 \mathrm{~mm}$, w/b ratios of $0.41,0.42,0.43$ and 0.45 and cement contents ranging from 337 to $382 \mathrm{~kg} / \mathrm{m}^{3}$; the objective being to obtain different accelerated corrosion rates. This was achieved by varying the amount of admixed $\mathrm{NaCl}$ (from 0 to $7.2 \mathrm{~kg} / \mathrm{m}^{3}$ ). The specimens were exposed to outdoor conditions during the test period. $i_{\text {corr }}$ was measured using the LPR technique (3LP and Gecor devices were used). Liu and Weyers found out that the dynamic corrosion process of steel in in-service concrete is a function of the chloride content, temperature, resistivity of the concrete and active corrosion time. The outcome of statistical analyses of the results was a non-linear regression $i_{\text {corr }}$ prediction model presented as shown in Eqn. (5):

$$
i_{\text {corr }}=102.47+10.09 \ln (1.69 C l)-39038.96\left(T^{-1}\right)-0.0015 R_{c}+290.91 t^{-0.215}
$$

where $i_{\text {corr }}$ is the 3LP corrosion rate $\left(\mu \mathrm{A} / \mathrm{cm}^{2}\right), C l$ is the total chloride content at the steel level $\left(\mathrm{kg} / \mathrm{m}^{3}\right), T$ is the temperature at the steel surface $(\mathrm{K}), R_{c}$ is the resistivity of the cover concrete $(\Omega)$ and $t$ is the corrosion time (years). The following can be noted with respect to Katwan et al.'s model [19]: 
- Although concrete cover was a variable in the experimental set up, it is not an input parameter in the model. This was based on a statistical analysis of the results, but may also be partly due to the use of admixed chlorides. The absence of cover as an input parameter in the proposed model suggests that it has no influence on $i_{\text {corr }}$; this stands in contrast to results reported by various researchers indicating that concrete cover affects both corrosion initiation and its propagation [e.g. 22, 23].

- Similar to previous models discussed, it is not clear whether the $i_{\text {corr }}$ predicted by the model is a constant $i_{\text {corr }}$ or not.

\section{Duracrete model (1998)}

The Duracrete model [24] is an attempt to improve on Alonso et al.'s model [14] and proposes the incorporation of other $i_{c o r r}$-influencing factors by the introduction of coefficients/correction factors in the model as shown in Eqn. (6):

$$
i_{\text {corr }}=\frac{k_{\text {corr }}}{\rho(t)} F_{c l} F_{\text {Galv }} F_{\text {oxide }} F_{\text {Oxy }}
$$

where $k_{\text {cprr }}$ is a constant regression parameter $\left(10^{4}\right), F_{c l}, F_{\text {Galv }}, F_{\text {oxide }}$ and $F_{\text {Oxy }}$ are factors to take into account the influence of chloride content, galvanic effects, continuous formation and ageing of oxides and availability of oxygen on $i_{\text {corr }}$ respectively and $\rho(t)$ is the resistivity of concrete $(\Omega-\mathrm{m})$ at time $t . \rho(t)=$ $\rho_{o} f_{e} f_{t}\left(t / t_{o}\right)^{n}$; where $\rho_{o}$ is the resistivity of concrete $(\Omega-\mathrm{m})$ at time $t_{o}, n$ is a factor which takes into account the influence of ageing on $\rho_{o}, f_{e}$ is a factor which modifies $\rho_{o}$ to take into account the influence of the exposure environment and $f_{t}$ is a factor which takes into account the influence of the resistivity test method. The following can be noted with respect to the Duracrete model:

- Even though the Duracrete model [24] attempted to improve on Alonso et al.'s model [14], it is still inherently susceptible to criticisms similar to those for Alonso et al.'s model as they are based on the same background.

- Although the above mentioned $i_{c o r r}$-influencing factors are suggested, no mention is made with respect to their quantification i.e. no guidelines are given on how to obtain or predict the values.

- It is not clear whether the $i_{\text {corr }}$ predicted by the model is a constant $i_{\text {corr }}$ or not.

\section{Vu and Stewart's model (2000)}

$\mathrm{Vu}$ and Stewart [25] developed an $i_{\text {corr }}$ prediction model based on the assumption that $\mathrm{O}_{2}$ availability at the steel surface (which depends on, among other factors, concrete quality, cover depth and environmental conditions such as temperature and relative humidity) are the governing factors. This was due to the consideration that for many locations in Australia, US, Europe and Asia, the average relative 
humidity (RH) is $>70 \%$. For an ambient $\mathrm{RH}$ of $75 \%$ and a temperature of $20{ }^{\circ} \mathrm{C}$, the influence of w/b ratio and cover depth $(C$, in $\mathrm{cm})$ on corrosion rate up to 1 year $\left(i_{\operatorname{corr}(1)}, \mu \mathrm{A} / \mathrm{cm}^{2}\right)$ after the end of the corrosion initiation phase was expressed empirically as shown in Eqn. (7):

$$
i_{\text {corr }(1)}=\frac{37.8(1-w / b)^{-1.64}}{C}
$$

During the propagation phase $i_{\text {corr }}$ is expressed as follows (Eqn. (8)):

$$
i_{\text {corr }}=i_{\text {corr }(1)} 0.85 t_{p}^{-0.29}=\left(\frac{32.13(1-w / b)^{-1.64}}{C}\right) t_{p}^{-0.29}
$$

where $t_{p}=t-t_{i} ; t$ is the time to which $i_{\text {corr }}$ is to be predicted and $t_{i}$ is the time to corrosion initiation. Plotting Eqn. (8) as shown in Figure 3 indicates that the model results in a constantly decreasing $i_{\text {corr }}$ with time; this is contrary to the expected peak variations in $i_{\text {corr }}$ depending on the prevailing concrete and exposure conditions, which vary from time to time. In addition, the initial $i_{\text {corr }}$ is at the start of corrosion propagation is unexpectedly high.

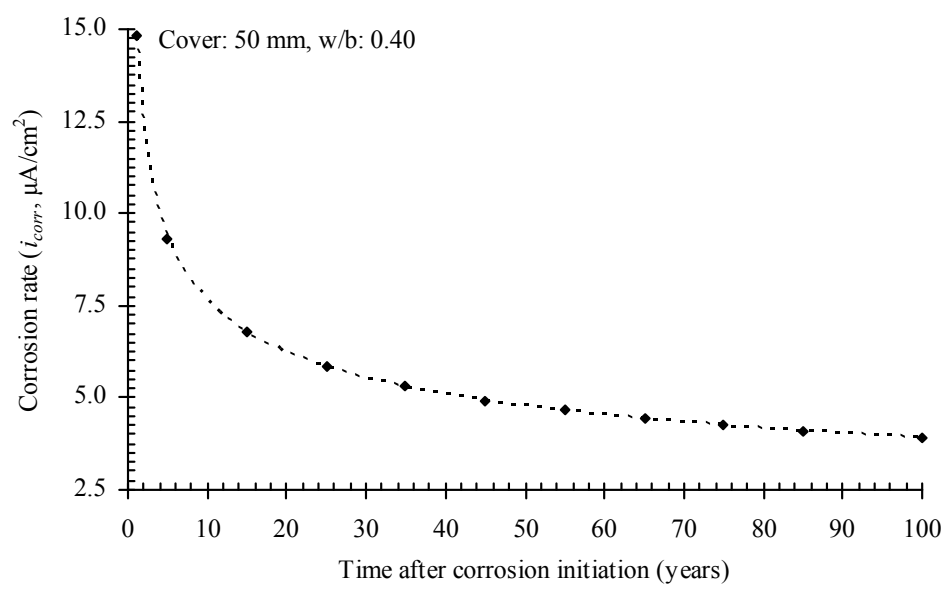

Figure 3: Variation of predicted $i_{\text {corr }}$ with time as per $\mathrm{Vu}$ and Stewart's model [25]

Furthermore, it is necessary to note the following:

- The model does not take into account the variation in concrete quality with change in binder type, at a constant $\mathrm{w} / \mathrm{b}$ ratio. 
- The model may be limited to corrosion processes where cathodic reaction (oxygen availability) is the governing reaction e.g. PC concretes; it may not be applicable to those where concrete resistivity (anodic reaction) is the governing reaction e.g. blended cement concretes [22].

Later in 2005, Vu et al. [26] attempted to improve Vu and Stewart's model [25] to account for the time-variant nature (i.e. peak variation of $i_{\text {corr }}$ with time) of $i_{\text {corr }}$ by replacing the constants ' 0.85 ' and ' 0.29 ' with constants ' $\alpha$ ' and ' $\beta$ ' respectively (Eqn. (9)) whose values depend on whether the $i_{\text {corr }}$ is time-variant or not:

$$
i_{\text {corr }}=\left(\frac{37.8(1-w / b)^{-1.64}}{C}\right) \alpha t_{p}^{\beta}
$$

The respective values for $\alpha$ and $\beta$ and are given below:

\begin{tabular}{lccc}
\hline Nature of $i_{\text {corr }}$ & $\alpha$ & $\beta$ & Reference \\
\hline Time-invariant & 0.85 & -0.29 & {$[25]$} \\
Time-variant & 1.0 & 0 & {$[26]$} \\
\hline
\end{tabular}

\section{Scott's model (2004)}

Scott's model [27] was developed using results from an experimental set-up comprising of cracked beam specimens $(120 \times 120 \times 375 \mathrm{~mm})$ with 0.2 and 0.7 $\mathrm{mm}$ crack widths, 20 and $40 \mathrm{~mm}$ concrete covers, a constant $\mathrm{w} / \mathrm{b}$ ratio of 0.58 and a variety of binder types: 25/75 PC/GGBS, 50/43/7 PC/GGBS/Silica fume (SF), 50/50 PC/GGBS, 70/30 PC/FA, 75/25 PC/GGBS, and 93/7 PC/SF. The proposed $i_{\text {corr }}$ prediction model was expressed as shown in Eqn. (10):

$$
i_{\text {corr }}=\left(1.43 \frac{C_{c}}{f}+0.02\right) \mathrm{e}^{\left[\left(\frac{40-x}{20}\right) 1.2\left(\frac{C_{c}}{f}\right)^{3}\right]}
$$

where $f$ is a slag correction factor, $f=10^{(|0.5-S|-0.5+S)}$ (where $S$ is the slag concentration expressed as a decimal e.g. 0.25 for $25 \%), C_{c}$ is the 90 day chloride conductivity index value $(\mathrm{mS} / \mathrm{cm})$ [28] and $x$ is the concrete cover depth (mm). A plot of Eqn. (10) is presented in Figure 4. 


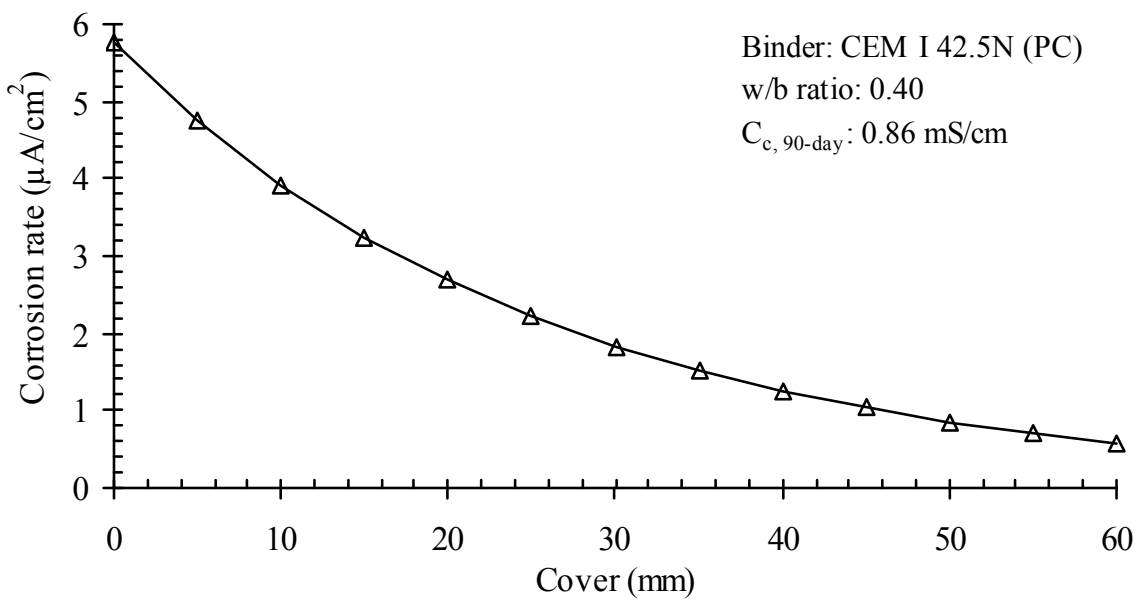

Figure 4: Plot of Scott's prediction model (values from [18])

The following are notable with respect to Scott's model:

- Although the model was developed using data from cracked specimens, it does not explicitly incorporate crack width as an input parameter. The applicability of this model to different scenarios other than those used during its development has not been conclusively ascertained in subsequent similar studies e.g. in Otieno et al.'s [18] study.

- Similar to other models already discussed, it is not clear whether the $i_{\text {corr }}$ predicted by the model is a constant $i_{\text {corr }}$ or not.

- Scott's model, similar to Alonso et al.'s [14], also underscores the possibility of using concrete resistivity (or its inverse conductivity) as a potential durability indicator and hence a service life prediction model input parameter.

\section{Martinez and Andrade's model (2009)}

Martinez and Andrade's model [29] can be used to predict an annual-averaged representative corrosion rate $\left(i_{\text {corr,rep }}\right)$. The model, similar to Alonso et al.'s model [14], is based on concrete resistivity. The determination of $i_{\text {corr,rep }}$ (defined by Eqn. (11)) involves a series of steps described in [29]:

$$
i_{\text {corr }, \text { rep }}=\frac{i_{\text {corr }, \text { sin } g l e}+i_{c o r r, \max }}{2}
$$

where $i_{\text {corr, } \max }$ is the maximum predicted $i_{\text {corr }}$ corresponding to a minimum resistivity $\left(\rho_{\min }\right)$ determined using in-situ cores, conditioned to $85 \% \mathrm{RH}$ (for 
structures sheltered from rain) or vacuum water-saturated (for non-sheltered or submerged ones).

This model, similar to $\mathrm{Vu}$ and Stewart's model [25], assumes that corrosion is anodic- or resistivity-controlled, a phenomenon that may only be the case in high resistivity concretes e.g. in blended cement concretes [22]. Furthermore, even in situations where the corrosion process is anodic-controlled, differences may still arise for varied concrete qualities or in situations where the concrete cover is cracked $[18,22]$.

\section{Models based on electrochemical principles of corrosion}

These models rely mostly on solving the governing (Laplace) equation to determine the distribution of electric potential on the steel surface based on the assumptions of electrical charge conservation and isotropic conductivity $[11,30]$. The governing equation can be presented as shown in Eqn. (12):

$$
\frac{\partial^{2} \phi}{\partial x^{2}}+\frac{\partial^{2} \phi}{\partial y^{2}}=\nabla^{2} \phi=0
$$

where $x$ and $y$ are planar Cartesian co-ordinates, $\phi$ is the electric potential and $\nabla$ is the Laplacian/harmonic operator. The governing equation is solved using relevant boundary conditions (e.g. concrete resistivity, oxygen diffusion and $\mathrm{pH}$ of the pore solution), and suitable numerical methods such as finite element method, finite difference method and boundary element method. A model developed using this method cannot be presented as a single mathematical equation. The $i_{c o r r}$ is determined from the potential distribution on the steel surface. The theory of electrochemical corrosion of steel is well established and can be found in the literature [11, 31]. Examples of models developed using this approach include those by Isgor and Razaqpur [11], Kim and Kim [30] and Dao et al. [32]. Specific details with respect to the principles of electrochemical corrosion and the determination of the input parameters and boundary conditions used to solve the governing (Laplace's) equation can be found in the literature [e.g. 11, 30, 31, 32].

From the on-going discussion, it is evident that models based on the application of electrochemical principles of corrosion, similar to others such as Katwan et al.'s model [19], rely on potential measurements. This has inherent disadvantages as discussed in previous sections. Therefore, validation of these models is important before they can be reliably used to predict $i_{c o r r}$. This will be covered in detail in the next section. 


\section{Summary of Salient Aspects to Be Considered When Developing a Corrosion Rate Prediction Model}

A number of prediction models by different researchers, based on different approaches, have been presented, discussed and critiqued in the previous sections. The following section will present a summary of the salient issues related to these models.

\section{Time-variant nature of corrosion rate}

Corrosion rate in RC structures is affected by several factors (e.g. concentration of chlorides, concrete penetrability) that vary from time to time and with continued aging of the structure. Consequently, $i_{c o r r}$ is also expected to show a similar variability and should be treated as such. This phenomenon has been appreciated by some researchers [e.g. 12, 33] but is yet to be successfully incorporated in prediction models. Researchers such as Yuan et al. [34] have proposed three distinct phases for a time-variant $i_{\text {corr }}$ as (i) descent phase, (ii) steady phase and, (iii) ascent phase (Figure 5).

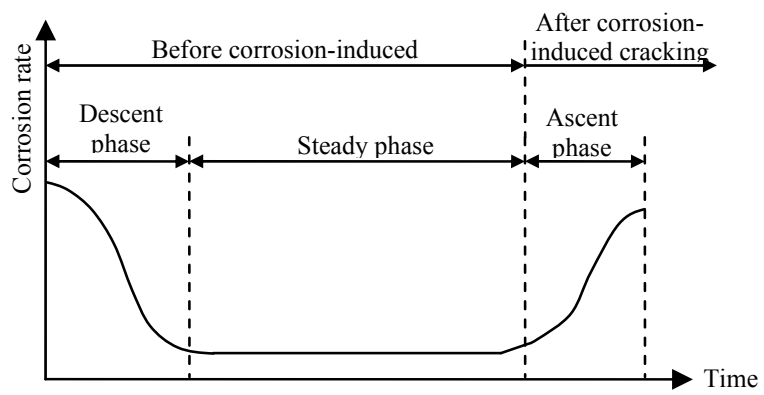

Figure 5: Phases of time-variant corrosion rate [34]

However, it is clear that such a trend cannot be used to generalize $i_{\text {corr }}$ trend in RC structures. $i_{\text {corr }}$ varies depending on the prevailing concrete and exposure conditions and hence will vary from one structure and exposure condition to another. Furthermore, the following can be noted:

- The proposed generalised trend may only be valid under the experimental set-up used by Yuan et al. Several other possible trends are possible depending on both the concrete and exposure conditions.

- In order to develop a more realistic generalised trend, the experimental set-up should be representative of the real RC structure and exposure conditions.

- It would be useful to the practicing engineer if approximate time periods and the corresponding corrosion rates for each phase are provided; this can also be used to plan for inspections and maintenance actions. 
The variation of $i_{\text {corr }}$ with time can be taken into account by incorporating the factors that affect it (as summarised in [10]) directly or indirectly as mentioned previously.

\section{Influence of cover cracking on corrosion rate}

Previous studies have shown that pre-corrosion cracking and crack characteristics can significantly influence both corrosion initiation and its propagation $[18,22]$. The effect of cracking on corrosion may vary depending on concrete quality, concrete resistivity, crack width, crack density, crack self-healing and crack orientation. The effect of load-induced crack width, concrete quality (binder type and $\mathrm{w} / \mathrm{b}$ ratio) and concrete resistivity on $i_{\text {corr }}$, obtained from an experimental study by Otieno et al. [18] can be summarised as presented in Figure 6.

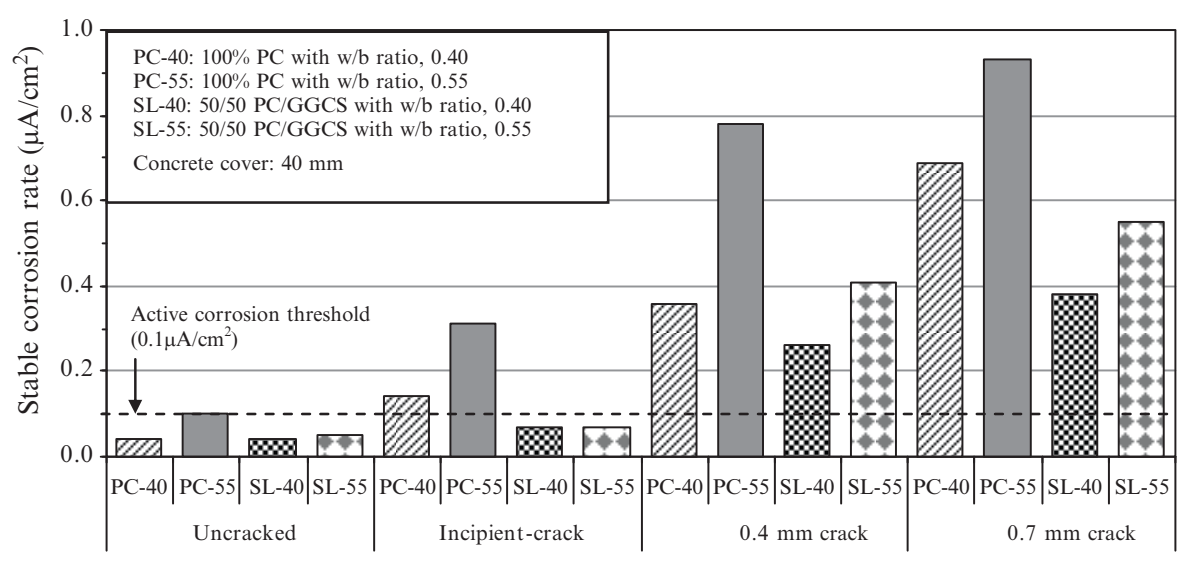

Figure 6: Effect of crack width and concrete quality on chloride-induced $i_{\text {corr }}[18]$

The study comprised of $100 \times 100 \times 500 \mathrm{~mm}$ beam specimens from four concrete mixes made using two w/b ratios $(0.40$ and 0.55$)$ and two binder types $(100 \%$ CEM I 42.5N (PC) and 50/50 PC/Corex slag (GGCS) blend. Details relating to GGCS can be found in [35]). A constant concrete cover of $40 \mathrm{~mm}$ was used. The beam specimens were pre-cracked (including the incipient cracks, being cracks that effectively had zero crack width) before being subjected to a cycle of 3-day wetting (with $5 \% \mathrm{NaCl}$ ) and 4-day air-drying under laboratory conditions (16-24 ${ }^{\circ} \mathrm{C}$ and $60-75 \%$ relative humidity) for a period of 32 weeks. From the study, the following conclusions were drawn:

- The initiation phase may either be substantially shortened or completely eliminated depending on crack width, concrete quality and resistivity.

- Cracking affects the $i_{\text {corr }}$ during the propagation phase but the extent depends on the interaction between crack width, concrete quality and concrete resistivity. 
To demonstrate the significance of the effect of crack width, concrete quality and resistivity on $i_{\text {corr }}$, Alonso et al.'s model [14], Eqn. (2), is compared with results obtained in a study by Otieno et al. [36] (

Figure 7).

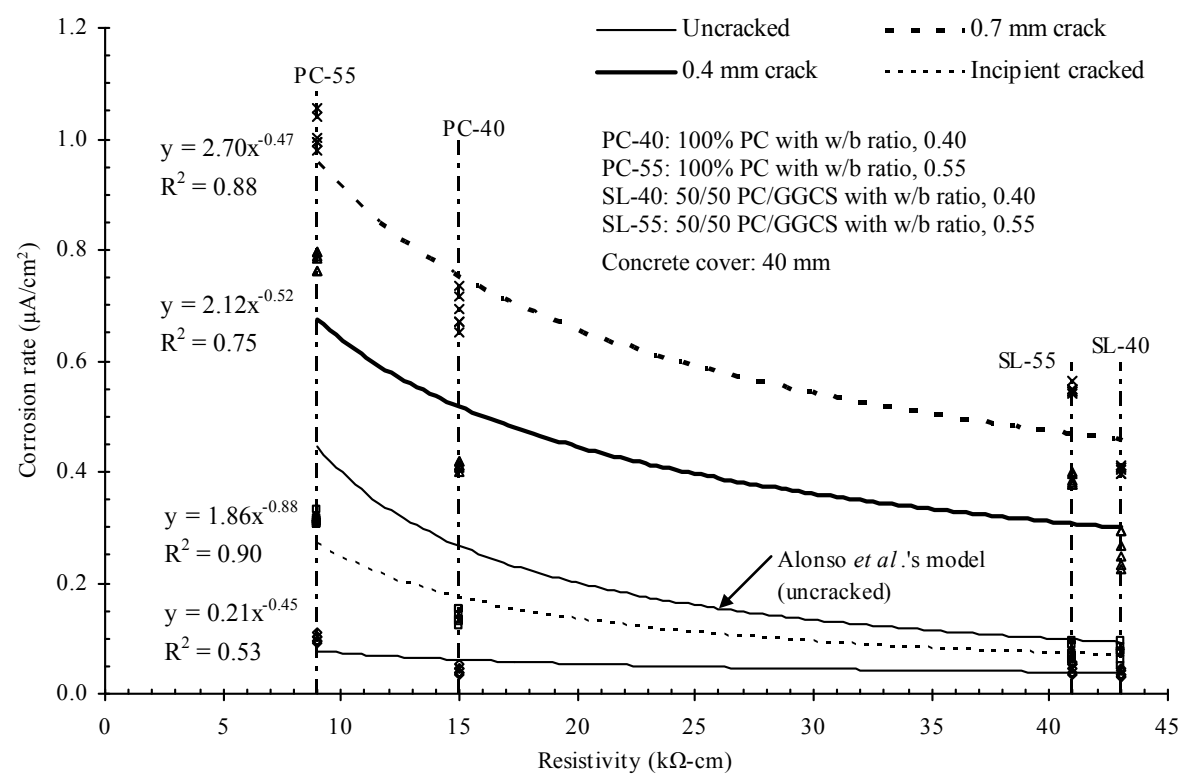

Figure 7: Effect of cracking, concrete quality and resistivity on $i_{\text {corr }}$ (comparison of Alonso et al.'s model [14] and Otieno's results [37])

Even though the experimental set-ups in the two studies are different, this comparison shows that crack width, concrete quality and resistivity are significant factors when predicting $i_{c o r r}$. Concluding from the data presented in Figure 7 , the relationship between $i_{\text {corr }}$ and concrete resistivity $(\rho)$ may be expressed as (Eqn. (13)):

$$
i_{\text {corr }}=k \rho^{-m}
$$

where $k$ and $m$ are coefficients depending on crack width, concrete quality and/or resistivity. It is therefore important that cracking, among other factors that affect corrosion rate [10], are incorporated in $i_{\text {corr }}$ prediction models. However, it is important to note that both Alonso et al. and Otieno et al.'s data were obtained from accelerated tests and should be verified with natural corrosion results. 


\section{Corrosion rate measurement techniques}

Different assessment techniques and instruments can be used to quantify $i_{\text {corr }}$ both in the laboratory and in the field. However, significant differences have been reported between different instruments when used to measure $i_{\text {corr }}$ under the same conditions [12, 38]. For example, Liu and Weyers' [12] reported that the difference among three $i_{\text {corr }}$ assessment techniques (gravimetric, 3LP and Gecor) was more than an order of magnitude; up to a factor of 17 with the 3LP being highest (Figure 8).

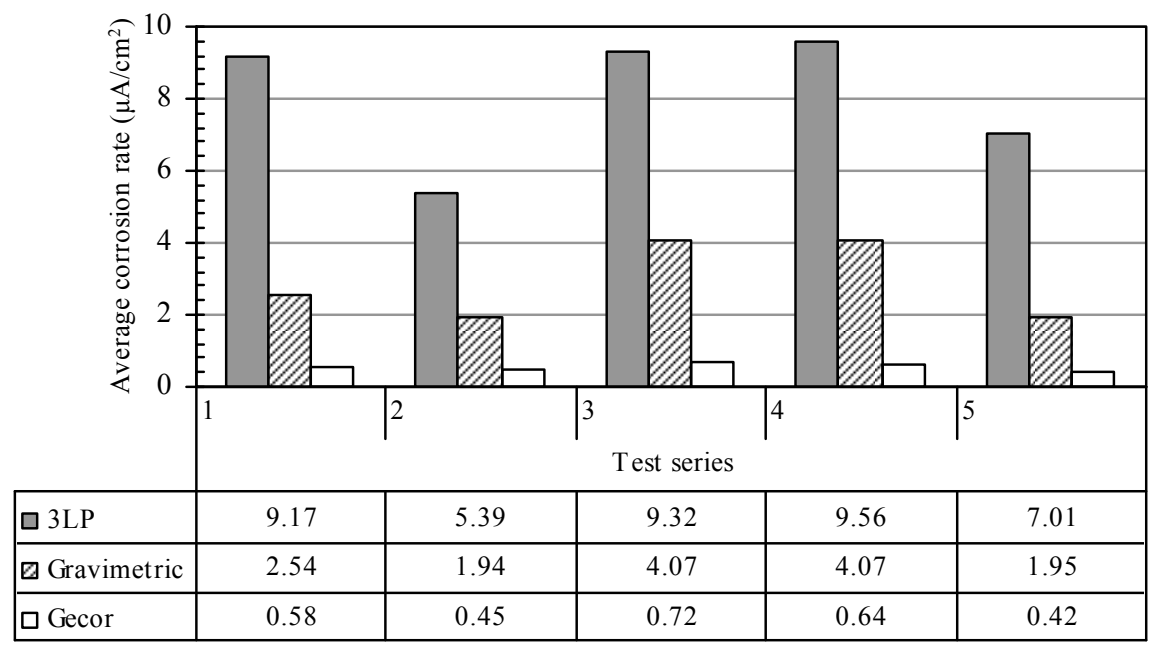

Figure 8: Average $i_{\text {corr }}$ from different assessment techniques [Data from 12]

It is therefore important that the assessment technique used to obtain the $i_{\text {corr }}$ data used during the model development stage is clearly stated. In this way, adjustments can be made to obtain relevant $i_{\text {corr }}$ values for use in the model. General guidelines for interpreting the results of the 3LP and Gecor are summarized in Table I [39, 40]. It must be noted that the interpretation guidelines for 3LP readings given in Table I may not be applicable to certain concrete and/or exposure conditions e.g. cracked concrete.

Table I: Gecor and 3LP interpretation guidelines [39, 40]

\begin{tabular}{cl|cl}
\hline $\begin{array}{c}i_{\text {corr }} \\
\left(\mu \mathrm{A} / \mathrm{cm}^{2}\right)\end{array}$ & $\begin{array}{c}\text { Gecor } \\
(\text { corrosion state) }\end{array}$ & $\begin{array}{c}i_{\text {corr }} \\
\left(\mu \mathrm{A} / \mathrm{cm}^{2}\right)\end{array}$ & $\begin{array}{c}\text { 3LP } \\
\text { (expected damage) }\end{array}$ \\
\hline$<0.1$ & Passive & $<0.2$ & No damage expected \\
$0.1-0.5$ & Low corrosion & $0.2-1.1$ & Damage expected in 10-15 years \\
$0.5-1.0$ & Moderate & $1.1-11$ & Damage expected in 2-10 years \\
$>1.0$ & High corrosion & $>11$ & Damage expected in < years \\
\hline
\end{tabular}


Furthermore, in addition to the $i_{\text {corr }}$ values differing from one measurement technique to another, they also differ from the actual (gravimetric) values. In the example presented here (Figure 8), the Gecor and 3LP $i_{\text {corr }}$ values are conspicuously higher (up to $261 \%$ ) and lower (up to $84 \%$ ) respectively than the gravimetric results (which are usually used in the laboratory to depict actual $i_{c o r r}$ ).

In addition to different assessment techniques giving different results under the same measurement conditions, other techniques e.g. HCP measurement have been reported to give varied results depending on the measurement conditions. With respect to HCP, studies have shown that there is no general correlation between $i_{\text {corr }}$ and HCP [21]. Furthermore, the HCP values can only be interpreted to give the likelihood or expected severity of corrosion in the structure. The use of such a measurement technique to obtain data for model development (for example as done by Katwan et al. [19]), may therefore not be ideal.

In general, $i_{\text {corr }}$ results from different corrosion assessment techniques should be carefully interpreted and/or compared bearing in mind the technique employed.

\section{Validation of models}

Performing accelerated corrosion experiments has become a common technique to simulate corrosion-induced damage in RC structures, mainly because results can be obtained within a short period of time. However, this technique has been criticised for not being representative of the natural corrosion process and hence the results obtained from such tests may not be reliably extended to real structures [41, 42]. Taking into consideration that most of the $i_{\text {corr }}$ prediction models are developed using results from accelerated experiments [e.g. 12, 14, 17, 18, 25, 27], it is important that to validate them using real/natural $i_{\text {corr }}$ data. This is an important stage in ensuring that the model is representative of the actual performance of inservice RC structures.

\section{Accounting for variability}

Variability of model input parameters is important and should be modelled in such a way that realistic results, and hence decisions, can be derived from the model. In order to adequately account for the variability in $i_{c o r r}$, it is important that the variability of the $i_{c o r r}$-influencing factors such as cover depth, cracking and concrete quality are first taken into consideration. The outcome of such an approach should be expected $i_{c o r r}$ trend-ranges/envelopes and not single ones.

However, accounting for variability should not only be taken to mean a statistical analysis of the $i_{\text {corr }}$ data, regardless of how rigorous the process may be. It requires availability of not only a representative sample but also accurate and reliable data. . None of the available models covered in the previous sections is based on probabilistic analysis. The development of a probabilistic model has been hindered 
mainly by lack of adequate data to determine relevant statistical distributions for the various $i_{c o r r}$-influencing parameters [24]. Further, the available data must be compatible with each other especially with respect to the measurement techniques.

Taking into consideration the critique on the use of accelerated corrosion experiments discussed above, it may be debatable as to whether a probabilistic model developed using data from an accelerated corrosion testing regime is valid or not to be applied to real structures. The use of natural $i_{\text {corr }}$ data would be ideal but in its absence, using data from accelerated tests appear acceptable subject to the model being validated in future as natural $i_{c o r r}$ data becomes available.

\section{Future Outlook (Ongoing Study)}

The review presented in this paper was motivated by an ongoing study to develop a chloride-induced $i_{\text {corr }}$ prediction model. The impetus for the study emanates from the need to quantify the corrosion propagation phase $\left(t_{p}\right)$ of the service life of corrosion-affected RC structures; this can assist in the development of pro-active maintenance and repair strategies. Furthermore, the need to improve on some of the shortcomings of the existing models discussed in this paper must be pointed out. A brief summary of the ongoing study is presented in the next sections.

\section{Objectives and expected outcomes of the study}

The main objectives of the ongoing study are to:

1. Develop a finite element numerical $i_{\text {corr }}$ prediction model for chloride-induced $t_{p}$ in RC structures. The model will be developed based on the findamental electrochemical corrosion principles, and implemented using a commercially available finite element modelling software.

2. Validate the model using both laboratory and in-situ natural corrosion assessment data. This will involve $(i)$ detailed comparison of the numerical model results with the in-situ and laboratory results, and (ii) modifying the model, if necessary, to fit into the in-situ corrosion rate results.

3. Integrate the model into an existing corrosion-induced damage model to obtain a comprehensive/complete service life prediction incorporating both the initiation and propagation phases of corrosion.

Important aspects of the study, in a bid to improve on some of the shortcomings of the available model discussed in this paper, are as follows:

(i) Combined effect of crack width, concrete cover and concrete quality on corrosion rate. Concrete quality will be quantified using the durability index tests [43] (chloride conductivity, oxygen permeability and water sorptivity).

(ii) Use of natural corrosion results to validate the numerical model (see next section for details). 
(iii) The inherent variability of corrosion rate will be accounted for by carrying out a stochastic analysis on the corrosion-influencing parameters viz concrete cover, crack width and concrete quality.

It is envisaged that at the end of the study, with the above objectives met, the following outcomes will be realised:

(i) Provision of recommendations with respect to pro-active conservation (maintenance and repair) strategies that can be undertaken to either attain the initial design service life (incorporating $t_{p}$ ) or extend it.

(ii) Determination of corrosion acceleration factors to relate accelerated (laboratory) and in-situ/field corrosion rates; this will enable the determination of equivalent natural corrosion rates from accelerated corrosion rates.

(iii) Inclusion of principles for obtaining performance diagnosis and prognosis of $\mathrm{RC}$ structures from corrosion assessment techniques and prediction models.

\section{Framework and scope of the study}

The study focuses on the quantification of the effect of crack width, concrete quality (binder type and $\mathrm{w} / \mathrm{b}$ ratio) and concrete cover on $i_{c o r r, C l}$. The experimental variables include: binder type (100\% CEM I 42.5N (PC), 50/50 PC/GGBS and $70 / 30 \mathrm{PC} / \mathrm{FA}), \mathrm{w} / \mathrm{b}$ ratio $(0.40$ and 0.55$)$, concrete cover $(20$ and $40 \mathrm{~mm})$ and crack width (uncracked, incipient-cracked, $0.4 \mathrm{~mm}$ and $0.7 \mathrm{~mm}$ ). For each binder type, concrete cover, crack width and w/b ratio, three beam specimens $(120 \times 130 \times 375$ mm long) will be made.

The cracked specimens will be pre-cracked under 3-point flexural machine loading. Thereafter, the respective crack widths (except the incipient crack) will be maintained using the 3-point loading rig shown in Figure 9. All the 0.4 and $0.7 \mathrm{~mm}$ cracked specimens will remain in individual loading rigs for the duration of the experimental programme. Parallel experiments will be run in the laboratory (accelerated corrosion) and in the field (natural corrosion in a spray/splash marine zone) in an attempt to establish the correlation between accelerated laboratory and natural field corrosion rates.

A series of corrosion assessments will be carried out on the specimens: $i_{\text {corr }}$, HCP, concrete resistivity and visual inspections. In addition, relevant tests will be performed to characterise both the fresh and hardened concretes.

In summary, the ongoing study will directly or indirectly simultaneously incorporate the following $i_{\text {corr }}$-influencing factors in the resulting prediction model: concrete quality, crack width, sustained loading, temperature, moisture content and cover depth. Ultimately, an improved and validated $i_{c o r r}$ model is expected to be developed at the end of the study. 


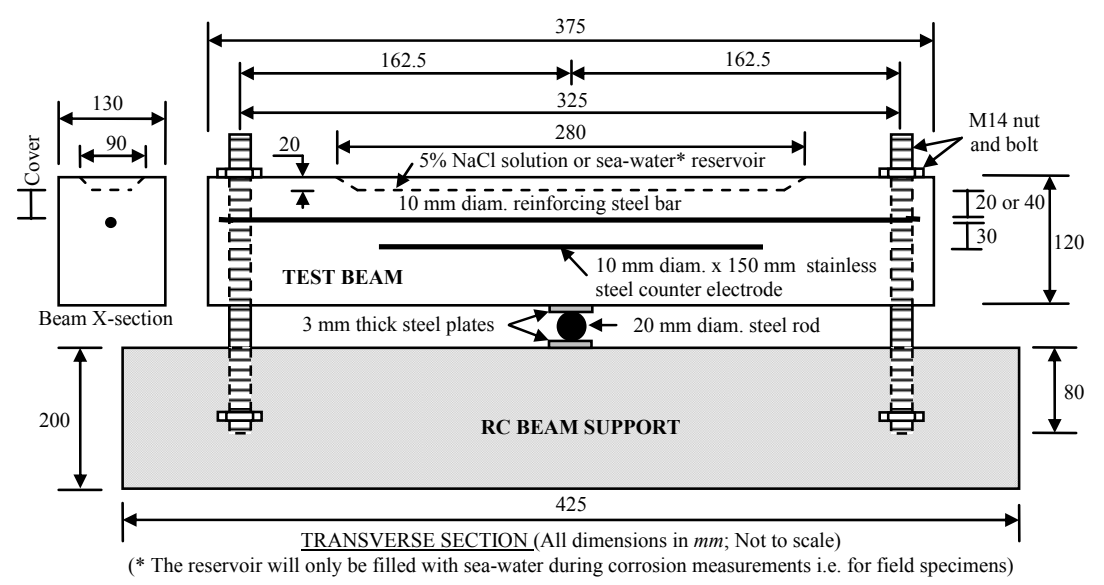

Figure 9: Beam loading set-up for 0.4 and $0.7 \mathrm{~mm}$ cracked specimens

\section{Closure}

Different aspects of various corrosion rate prediction models were reviewed in this paper. In summary, the following points can be made:

(i) Corrosion rate is one of the most important input parameters in corrosioninduced damage prediction and should therefore receive sufficient attention with respect to its assessment and prediction.

(ii) Corrosion-influencing factors such as cover cracking, resistivity, concrete quality and cover depth should be (explicitly) incorporated in corrosion rate prediction models.

(iii) Realistic prediction models and/or clear definition of corrosion rate and its assessment are needed to predict the actual performances of corrosionaffected RC structures. In addition, a clear definition of acceptable corrosioninduced damage levels should be made a priori.

(iv) Model validation using data from natural corrosion is a vital stage in model development especially for numerically developed models and those developed using data from accelerated corrosion tests. Therefore, both field/laboratory data should be combined with modelling to develop reliable corrosion rate prediction models.

(v) The inherent variability of corrosion rate and the factors influencing it should be accounted for in prediction models using probabilistic methods.

(vi) The ongoing (laboratory and field) study presented in this paper will attempt to address some of the salient corrosion-influencing factors presented by taking into account cover cracking, cover depth and concrete quality (binder type, $\mathrm{w} / \mathrm{b}$ ratio). The variability of these factors will also be accounted for using a probabilistic approach. 


\section{References}

[1] Raupach, M. (2006) Models for the propagation phase of reinforcement corrosion - an overview. Materials and Corrosion, 57(8), pp. 605-612.

[2] Redaelli, E., Bertolini, L., W., Peelen \& Polder, R. (2006) FEM-models for the corrosion propagation period of chloride-induced reinforcement corrosion. Materials and Corrosion, 57(8), pp. 628-634.

[3] Warkus, J., Brem, M. \& Raupach, M. (2006) BEM-models for the corrosion propagation period of chloride-induced reinforcement corrosion. Materials and Corrosion, 57(8), pp. 636-641.

[4] Zhang, R., Castel, A. \& Francois, R. (2009) Serviceability limit state criteria based on steel-concrete bond loss for corroded reinforced concrete in chloride environment. Materials and Structures, Vol. 42, pp. 1407-1421.

[5] Torres-Acosta, A. A., Navarro-Guitierrez, S. \& Teran-Guillen, J. (2007) Residual flexure capacity of corroded reinforced concrete beams. Engineering Structures, Vol. 29, pp. 1145-1152.

[6] Liu, Y. \& Weyers, R. E. (1998) Modelling the time-to-corrosion cracking in chloride contaminated reinforced concrete structures. ACI Materials Journal, 95(6), pp. 675-681.

[7] El Maaddawy, T. \& Soudki, K. (2007) A model for prediction of time from corrosion initiation to corrosion cracking. Cement \& Concrete Composites, 29(3), pp. 168-175.

[8] Li, C. Q., Melchers, R. E. \& Zheng, J. J. (2006) An analytical model for corrosion-induced crack width in reinforced concrete structures. $A C I$ Structural Journal, 103(4), pp. 479-487.

[9] Cox, D. R. (1958) Planning of experiments, John Wiley and Sons, Inc., New York.

[10] Otieno, M. B., Beushausen, H.-D. \& Alexander, M G. (2010) Corrosion propagation in reinforced concrete structures - state of the art review and way forward. Proceedings of the $6^{\text {th }}$ international conference on Concrete under severe conditions - Environment and loading, CONSEC'10. June $7^{\text {th }}-9^{\text {th }} 2010$, Merida, Yucatan, Mexico. Accepted for publication.

[11] Isgor, O., B. \& Razaqpur, A. G. (2006) Modelling steel corrosion in concrete structures. Materials and Structures, Vol. 39, pp. 291-302.

[12] Liu, T. \& Weyers, R. W. (1998) Modelling the dynamic corrosion process in chloride contaminated concrete structures. Cement and Concrete Research, 28(3), pp. 365-379.

[13] Song, X. \& Liu, X. (2000) Experiment research on corrosion of reinforcement in concrete through cathode-to-anode area ratio. ACI Materials Journal, 97(2), pp. 148-155.

[14] Alonso, C., Andrade, C. \& Gonzalez, J. A. (1988) Relation between resistivity and corrosion rate of reinforcements in carbonated mortar made with several cement types. Cement and Concrete Research, 18(5), pp. 687698. 
[15] Azad, A. K., Ahmad, S. \& Al-Gohi, B. H. A. (2010) Flexural strength of corroded reinforced concrete beams. Magazine of Concrete Research, 62(6), pp. 405-414.

[16] Andrade, C. (2009) Types of models of service life of reinforcement: the case of the resistivity. Proceedings of the $7^{\text {th }}$ Asia Pacific Structural Engineering and Construction Conference \& 2nd European Asian Civil Engineering Forum (APSEC / EACEF 2009). 4-6 August 2009, Langkawi, Malaysia, Kedah, Malaysia pp. 30-35.

[17] Yalcyn, H. \& Ergun, M. (1996) The prediction of corrosion rates of reinforcing steels in concrete. Cement and Concrete Research, 26(10), pp. 1593-1599.

[18] Otieno, M. B., Alexander, M. G. \& Beushausen, H. D. (2010) Corrosion in cracked and uncracked concrete - influence of crack width, concrete quality and crack re-opening. Magazine of Concrete Research, doi: 10.1680/macr.2008.62.00.1.

[19] Katwan, M. J., Hodgkiess, T. \& Arthur, P. D. (1996) Electrochemical noise technique for the prediction of corrosion rate of steel in concrete. Materials and Structures, 29(5), pp. 286-294.

[20] Page, C. L. \& Lambert, P. (1986) Analytical and electrochemical investigations of reinforcement corrosion. Contractor Report 30, Transport and Road Research Laboratory (TRRL), Crowthorne.

[21] Broomfield, J. P. (2007) Corrosion of steel in concrete - understanding, investigation and repair ( $2^{\text {nd }}$ Edition), Taylor \& Francis, Oxford, United Kingdom.

[22] Scott, A. N. \& Alexander, M. G. (2007) The influence of binder type, cracking and cover on corrosion rates of steel in chloride-contaminated concrete. Magazine of Concrete Research, 59(7), pp. 495-505.

[23] Bentur, A., Diamond, S. \& Berke, N. (1997) Steel corrosion in concrete, Fundamentals and Civil Engineering Practice, E \& FN Spon, London. pp. 41-43.

[24] Duracrete (1998) Probabilistic performance based durability design: modelling of degradation. Document, D. P. BE95-1347/R4-5, The Netherlands,

[25] Vu, K. \& Stewart, M. G. (2000) Structural reliability of concrete bridges including improved chloride-induced corrosion models. Structural Safety, 22(4), pp. 313-333.

[26] Vu, K., Stewart, M. G. \& Mullard, J. (2005) Corrosion-Induced Cracking: Experimental Data and Predictive Models. ACI Structural Journal, 102(5), pp. 719-726.

[27] Scott, A. N. (2004) The influence of binder type and cracking on reinforcing steel corrosion in concrete. PhD Thesis, Department of Civil Engineering, University of Cape Town.

[28] Streicher, P.E. \& Alexander, M. G. (1995) A chloride conduction test for concrete. Cement Concrete Research, 25(6), pp. 1284-1294. 
[29] Martínez, I. \& Andrade, C. (2009) Examples of reinforcement corrosion monitoring by embedded sensors in concrete structures. Cement \& Concrete Composites, Vol. 31, pp. 545-554.

[30] Kim, C. Y. \& Kim, J. K. (2008) Numerical analysis of localized steel corrosion in concrete. Construction and Building Materials, 22(6), pp. 11291136.

[31] Revie, R. W. \& Uhlig, H. H. (2008) Corrosion and Corrosion Control: An introduction to corrosion science and engineering, $4^{\text {th }}$ Edition, John Wiley \& Sons Inc., New Jersey, USA.

[32] Dao, L. T. N., Dao, V. T. N. \& Ann, K. Y. (2010) Modeling Steel Corrosion in Concrete Structures - Part 2: A Unified Adaptive Finite Element Model for Simulation of Steel Corrosion. International Journal of Electrochemical Science, Vol. 5, pp. 314-326.

[33] Melchers, R. E. \& Li, C. Q. (2006) Phenomenological Modeling of Reinforcement Corrosion in Marine Environments. ACI Materials Journal, 103(1), pp. 25-32.

[34] Yuan, Y., Ji, Y. \& Jiang, J. (2009) Effect of corrosion layer of steel bar in concrete on time-variant corrosion rate. Materials and Structures, Vol. 42, pp. 1443-1450.

[35] Mackechnie, J. R., Alexander, M. G. \& Jaufeerally, H. (1993) Structural and durability properties of concrete made with Corex slag, Research monograph No. 6, Department of Civil Engineering, University of Cape Town.

[36] Otieno, M. B., Alexander, M. G. \& Beushausen, H. D. (2010) Suitability of various measurement techniques for assessing corrosion in cracked concrete. Accepted for publication in the ACI Materials Journal.

[37] Otieno, M. B. (2008) Corrosion Propagation in Cracked and Uncracked Concrete. Masters Dissertation, Department of Civil Engineering, University of Cape Town.

[38] Breysse, D., Klysz, G., Derobert, X., Sirieix, C. \& Lataste, J. F. (2008) How to combine several non-destructive techniques for a better assessment of concrete structures. Cement and Concrete Research, 39, pp. 783-793.

[39] Clear, K. C. (1992) Measuring Rate of Corrosion of Steel in Field Concrete Structures. Transportation Research Board, Record No. 1211, Washington DC, pp. 28-37.

[40] Broomfield, J. P., Rodriguez, J., Ortega, L. M \& Garcia, A. M. (1993) Corrosion rate measurements in reinforced concrete structures by a linear polarization device. Proceedings of the International symposium on condition assessment, protection, repair, and rehabilitation of concrete bridges exposed to aggressive environments, ACI Fall Convention. $9^{\text {th }}-10^{\text {th }}$ November, Minneapolis, MN. pp. 644-651.

[41] Alonso, C., Andrade, C., Rodriguez, J. \& Diez, J. M. (1998) Factors controlling cracking of concrete affected by reinforcement corrosion. Materials and Structures, Vol. 31, pp. 435-441. 
[42] Andrade, C., Alonso, C. \& Molina, F. J. (1993) Cover cracking as a function of bar corrosion: Part I-Experimental test. Materials and Structures, Vol. 26, pp. 453-464.

[43] Alexander, M G., Ballim, Y. \& Mackechnie, J. R. (2001) Use of durability indexes to achieve durable cover concrete in reinforced concrete structures. Materials Science of Concrete, VI, pp. 483-511. 